\title{
Cointegration Analysis and ECM of Industrial Economy and Direct Foreign Investments of China
}

\author{
Ying Yin \\ Department of Economics and Management, Hunan Electrical College of Technology, Xiangtan Hunan, China. \\ Email: fa0256@126.com
}

Received 2013

\begin{abstract}
Based on cointegration theory and Granger causality test, applied on the gross domestic production of industry and direct foreign investments economic statistic data from 1983 to 2010 of China to analyze the long and steady dynamic equilibrium relations. Research results indicate that there is long-term stable one-way Granger causality relationship between the growth of gross domestic production of industry and direct foreign investments. The growth of direct foreign investments affect the growth of gross domestic production of industry, but industrial economic growth is not the reasons of the direct foreign investments.
\end{abstract}

Keywords: Growth of Gross Domestic Production of Industry; Analysis of Cointegration; Direct Foreign Investments

\section{Introduction}

Industrial economic growth is a major macroeconomic indicator to measure a country's overall level of economic development and national comprehensive strength. Gross domestic production of industry is the important part of GDP, and a country's economic development lies in the development of industry [1]. This paper analyses whether direct foreign investments is the causality of the growth of industrial economy. And the error correction model (ECM) is established for direct foreign investments and industrial economic growth, which plays an important role in analyzing direct foreign investments.

The data of direct foreign investments and the gross domestic production of industry from 1983 to 2010 are collected. This paper analyzes the relations between direct foreign investments and economic growth in industrial by using cointegration analysis and Granger-causality test theory methods. The results show that there is a long-term equilibrium relationship between direct foreign investments growth and industrial economic growth of China, and there is a one-way Granger-causality from direct foreign investments growth to industrial economic growth.

\section{Data Processing and Unit Root Test}

This data selected for analysis is from "China Statistical

"Fund Project: China Hunan Provincial Science \& technology Projects (2012FJ3030), The Vocational Education Subject of China Machinery Industry Education Association in 2011 under grant No. ZJJX$11 \mathrm{ZZ013.}$
Yearbook" (1990-2011). Let DFI denote the direct foreign investments, which reflects the overall growth of direct foreign investments. Let GDPI denote the gross domestic production of industry, which reflects the industrial economic growth.

Before cointegration test between GDPI and DFI, firstly test unit roots to determine whether the time series is stable. If the time series is unstable, the cointegration test will be making a spurious regression, leading incorrect conclusion. The growth of GDPI and DFI have the exponential trend and more consistent direction change trend, consistent changes rate and unstable characteristics. Through the ADF testing, GDPI and DFI is unstable. Since the natural logarithm transformation does not change the relationship of the original variables, and can make it linear trend, and eliminate heteroskedasticity in time series. Use software EViews6.0 to implement natural logarithm transformation on GDPI and DFI, and then implement differencing.

$$
\begin{aligned}
& L G D P I=\log (G D P I), \\
& L D F I=\log (D F I), \\
& \triangle L G D P I=\log (G D P I)-\log (G D P I(-1)), \\
& \triangle L D F I=\log (D F I)-\log (D F I(-1))
\end{aligned}
$$

ADF test on LGDPI and LDFI and $\triangle L G D P I$ and $\triangle L D F I$ with software EViews6.0. Shown as Table 1, the ADF statistics of $L G D P I$ and $L D F I$ is larger than the critical value of $5 \%$, which means the $L G D P I$ and $L D F I$ can not reject unit root hypothesis, indicating LGDPI and $L D F I$ is not significant at the $5 \%$ level, $L G D P I$ and $L D F I$ is unstable. The ADF statistics of $\triangle L G D P I$ and $\triangle L D F I$ is 
less than the critical value of $5 \%$, which means these variables are significant at the $5 \%$ level, reject unit root hypothesis, $\triangle L G D P I$ and $\triangle L D F I$ are stable.

\section{Cointegration Test Between the Variables}

The first difference series rejects unit root hypothesis, which shows a stable linear combination may exist in the time series LGDPI and LDFI. The linear combination reflects the relationship in the proportion of long-term stability of variables, which is cointegration relationship.

There are two cointegration test methods among the variables: one is Engle-Granger two-step test for cointegration test between two variables. Another method is Johansen test for cointegration test among multiple variables. Since this paper studies cointegration relationship between GDPI and DFI, so we would like to use EG two-step method to test the cointegration relationship.

Suppose $L G D P I$ and $L D F I$ are cointegrated, use software EViews6.0 to estimate the regression equation model, shown as Table 2.

The cointegration equation is obtained:

$$
\begin{aligned}
L_{G D P I_{t}} & =1.138355+0.810262 L D F I_{t} \\
& (2.843) \quad(17.875)
\end{aligned}
$$

In the EViews6.0: Series resid01= resid, apply ADF test to the resid01. Shown as Table 3.

Table 1. The stable test of each variable.

\begin{tabular}{ccccc}
\hline Variable & $\begin{array}{c}\text { Inspection } \\
\text { Type }(c, t, k)\end{array}$ & $\begin{array}{c}\text { Statistics } \\
\text { ADF }\end{array}$ & $\begin{array}{c}\text { Threshold } \\
\text { of 5\% }\end{array}$ & Stablity \\
\hline LGDPI & $(\mathrm{c}, \mathrm{t}, 6)$ & -1.0703 & -3.5875 & Unstable \\
LDFI & $(\mathrm{c}, \mathrm{t}, 6)$ & -2.6446 & -3.5875 & Unstable \\
$\Delta L G D P I$ & $(\mathrm{c}, 0,6)$ & -4.0821 & -2.9810 & Stable \\
$\Delta L D F I$ & $(\mathrm{c}, 0,6)$ & -4.1636 & -2.9810 & Stable \\
\hline
\end{tabular}

Note: $(c, t, k)$ denote the unit root test equation including the constant term and time trend and the order of lag, 0 does not include $c$ or $t$, adding lags are intended to make the residuals white noise.

Table 2. Regression equation of LDFI with LGDPI

\begin{tabular}{ccccc}
\hline \multicolumn{3}{c}{ Dependent Variable: LGDPI } & \multicolumn{2}{c}{ Method: Least Squares } \\
\hline & Sample (adjusted): 19832010 & \\
Variable & Coefficient & Std. Error & t-Statistic & Prob. \\
C & 1.138355 & 0.400428 & 2.842843 & 0.0086 \\
LDFI & 0.810262 & 0.045330 & 17.87474 & 0.0000 \\
R-squared & 0.924748 & Mean dependent var & 8.2367 \\
Adjusted R-squared & 0.921854 & S.D. dependent var & 0.97310 \\
S.E. of regression & 0.272026 & Akaike info criterion & 0.30291 \\
Sum squared resid & 1.923949 & Schwarz criterion & 0.39807 \\
Log likelihood & -2.240734 & F-statistic & 319.506 \\
Durbin-Watson stat & 0.525614 & Prob(F-statistic) & 0.00000 \\
\hline
\end{tabular}

From Table 3, the Augmented Dickey-Fuller test statistic value of -2.1466 is greater than the $5 \%$ critical value of -2.9763 , resid01 can not reject unit root test, series residuals resid01 is a non-stable.

Suppose $\triangle L G D P I$ and $\triangle L D F I$ are cointegrated, use softwore EViews6.0 to estimate cointegration equation of $\triangle L G D P I$ and $\triangle L D F I$. Shown as Table 4.

The cointegration Equation is:

$$
\begin{aligned}
\Delta L G \hat{D P I} I_{t} & =0.157832-0.265429 \Delta L D F I_{t} \\
& (4.638) \quad(-1.588)
\end{aligned}
$$

$D W$ statistic is about 1.727 near to 2. In Eviews6.0: series resid02 $=$ resid, resid02 is the random interference terms, to test for a unit root on the resid0 2.

Shown as Table 5. the Augmented Dickey-Fuller test statistic value of -4.2161 is less than the $1 \%$ critical value of -3.7115 , we can strongly reject the unit root hypothesis, resid02 residuals is a stable sequence.

\begin{tabular}{|c|c|c|c|c|}
\hline \multicolumn{3}{|c|}{ Dependent Variable: $\Delta$ LGDPI } & \multicolumn{2}{|c|}{ Method: Least Squares } \\
\hline \multicolumn{5}{|c|}{ Sample (adjusted): 19832010} \\
\hline Variable & Coefficient & Std. Error & t-Statistic & Prob. \\
\hline $\mathrm{C}$ & 0.157832 & 0.034027 & 4.638443 & 0.0001 \\
\hline$\Delta \mathrm{LDFI}$ & -0.265429 & 0.167203 & -1.587466 & 0.1250 \\
\hline R-squared & 0.091571 & \multicolumn{2}{|c|}{ Mean dependent var } & 0.11915 \\
\hline Adjusted R-squared & 0.055234 & \multicolumn{2}{|c|}{ S.D. dependent var } & 0.12697 \\
\hline S.E. of regression & 0.123417 & \multicolumn{2}{|c|}{ Akaike info criterion } & -1.27531 \\
\hline Sum squared resid & 0.380793 & \multicolumn{2}{|c|}{ Schwarz criterion } & -1.17932 \\
\hline Log likelihood & 19.21670 & \multicolumn{2}{|c|}{ F-statistic } & 2.52005 \\
\hline Durbin-Watson stat & 1.727173 & \multicolumn{2}{|c|}{ Prob(F-statistic) } & 0.12498 \\
\hline
\end{tabular}

Table 3. The Unit Root Test Results of resid01.

\begin{tabular}{ccc}
\hline \multicolumn{2}{c}{ Null Hypothesis: RESID02 has a unit root } \\
\hline \multicolumn{2}{c}{ t-Statistic } & \multicolumn{1}{c}{ Prob.* } \\
Augmented Dickey-Fuller test statistic & -2.1466 \\
Test critical values: & 1\% level & -3.6999 \\
& $5 \%$ level & -2.9763 \\
\hline
\end{tabular}

Table 4. Cointegration Equation of $\triangle L G D P I \quad$ with $\triangle L D F I$.

Table 5. The unit root test results resid02.

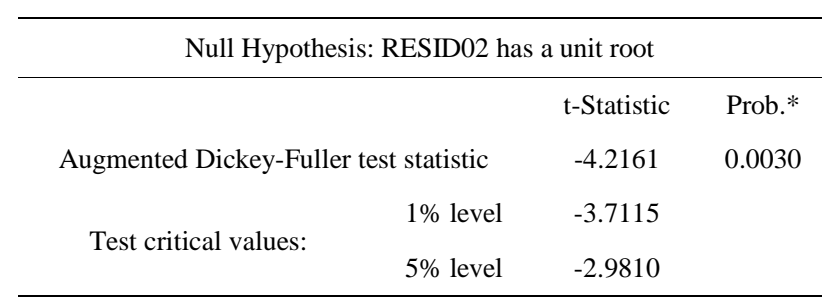


There is stable linear combination between the $\triangle L G D P I$ and $\triangle L D F I$, that is total direct foreign investments and gross domestic industrial production are cointegrated.

\section{Estimated Error Correction Model}

\subsection{First-Order Error Correction Model}

According to the Granger theorem, a set of variables with cointegration error correction model has the form of ECM expression. Therefore, based on the cointegration test, we can establish ECM that includes error correction term, in order to study the model of short-term dynamic and long-term cointegration features. It is known by cointegration test, there is cointegration relationship between gross domestic production of industry and direct foreign investments, although $D W$ statistic was significantly near to 2, indicating that there is not residual autocorrelation in the series. Therefore, we may re-establish regression equation of $L D F I$ and $L G D P I$, and add lagged variables, and establish a single ECM equation using EViews6.0:

The regressive equation is obtained:

$$
\begin{array}{r}
G D P I_{t}= \\
0.143642-0.193526 L D F I_{t}-0.157976 E C M_{t} \\
(4.1827) \quad(-1.1443)
\end{array}
$$

DW statistic is about 1.623 near to 2 , there is not residual autocorrelation in resid. In Eviews6.0: series resid03 $=$ resid, resid03 is the random interference terms, to test for a unit root on the resid03.

Shown as Table 7. The Augmented Dickey-Fuller test statistic value of 0.1312 is greater than the $5 \%$ critical value of -2.998 , resid03 can not reject unit root test, series residuals resid03 is a non-stable.

\begin{tabular}{|c|c|c|c|c|}
\hline \multicolumn{5}{|c|}{ Dependent Variable: D(LGDPI) } \\
\hline \multicolumn{5}{|c|}{ Method: Least Squares } \\
\hline Variable & Coefficient & Std. Error & t-Statistic & Prob. \\
\hline $\mathrm{C}$ & 0.143642 & 0.034342 & 4.182747 & 0.0003 \\
\hline $\mathrm{D}(\mathrm{LDFI})$ & -0.193526 & 0.169128 & -1.144259 & 0.2638 \\
\hline $\operatorname{ECM}(-1)$ & -0.157976 & 0.101703 & -1.553306 & 0.1334 \\
\hline R-squared & 0.174555 & \multicolumn{2}{|c|}{ Mean dependent var } & 0.119152 \\
\hline Adjusted R-squared & 0.105768 & \multicolumn{2}{|c|}{ S.D. dependent var } & 0.126973 \\
\hline S.E. of regression & 0.120071 & \multicolumn{2}{|c|}{ Akaike info criterion } & -1.29703 \\
\hline Sum squared resid & 0.346008 & \multicolumn{2}{|c|}{ Schwarz criterion } & -1.15305 \\
\hline Log likelihood & 20.50991 & \multicolumn{2}{|c|}{ F-statistic } & 2.53761 \\
\hline Durbin-Watson stat & 1.622968 & \multicolumn{2}{|c|}{ Prob(F-statistic) } & 0.10006 \\
\hline
\end{tabular}

Table 6. First-order ECM equation.

\subsection{Second-Order Error Correction Model}

Because $\triangle L D F I$ and $\triangle L G D P$ is cointegration, residuals autocorrelation exists in first order ECM, so the second order ECM could be estimated using EViews6.0.

The $t$ statistic of all varibles are over nine. $D W$ statistic is 1.6256 near to 2 , there is no residual serial autocorrelation. resid04 is the random interference terms, to test for a unit root on the resid04.

Shown as Table 9. the Augmented Dickey-Fuller test statistic value of -3.7507 is less than the $1 \%$ critical value of -3.7241 , we can strongly reject the unit root hypothesis, resid04 residuals is a stable sequence.

Table 7. The unit root test results resid03.

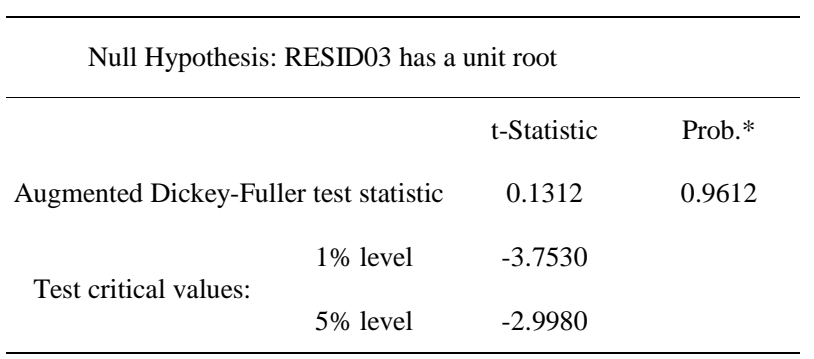

\begin{tabular}{|c|c|c|c|c|}
\hline \multicolumn{5}{|c|}{ Dependent Variable: D(LGDPI) } \\
\hline Variable & Coefficient & Std. Error & t-Statistic & Prob. \\
\hline $\mathrm{D}(\mathrm{LDFI})$ & -0.186079 & 0.166714 & -1.116153 & 0.2764 \\
\hline D(LGDPI(-1)) & 0.938924 & 0.226459 & 4.146107 & 0.0004 \\
\hline $\mathrm{D}(\mathrm{LDFI}(-1))$ & 0.227451 & 0.153518 & 1.481597 & 0.1526 \\
\hline ECM2(-1) & -1.193137 & 0.398539 & -2.993775 & 0.0067 \\
\hline R-squared & 0.162356 & \multicolumn{2}{|c|}{ Mean dependent var } & 0.123859 \\
\hline Adjusted R-squared & 0.048132 & \multicolumn{2}{|c|}{ S.D. dependent var } & 0.127063 \\
\hline S.E. of regression & 0.123968 & \multicolumn{2}{|c|}{ Akaike info criterion } & -1.196956 \\
\hline Sum squared resid & 0.338095 & \multicolumn{2}{|c|}{ Schwarz criterion } & -1.003402 \\
\hline Log likelihood & 19.56042 & \multicolumn{2}{|c|}{ Durbin-Watson stat } & 1.625600 \\
\hline \multicolumn{5}{|c|}{ Table 9. The unit root test results resid04. } \\
\hline \multicolumn{5}{|c|}{ Null Hypothesis: RESID04 has a unit root } \\
\hline & & & t-Statistic & Prob.* \\
\hline \multicolumn{3}{|c|}{ Augmented Dickey-Fuller test statistic } & -3.7507 & 0.0094 \\
\hline \multirow[b]{2}{*}{ Test critical values } & \multicolumn{2}{|c|}{$1 \%$ level } & -3.7241 & \\
\hline & \multicolumn{2}{|c|}{$5 \%$ level } & -2.9862 & \\
\hline
\end{tabular}

Table 8. Second-order ECM equation. 
Table 10. Granger causality test variables.

\begin{tabular}{ccc}
\hline Null Hypothesis: & F-Statistic & Probability \\
\hline LGDPI does not Granger Cause LDFI & 1.7311 & 0.2014 \\
LDFI does not Granger Cause LGDPI & 4.4247 & 0.0249 \\
\hline
\end{tabular}

The size of coefficient of the ecm reflects on the deviation from the adjustment of the long-run equilibrium. From the point of view of estimate coefficient of ecm, when the short-term fluctuations deviate from the longterm equilibrium, the adjustment will effects non-equilibrium state back to equilibrium with 1.193, which means that the non-equilibrium error rate of previous year makes amendments of direction on $\triangle L D F I$ with the rate of $119.3 \%$.

\section{Test the Granger-causality Between Va- riables}

From the view of the growth effect of variable, when analysis of Granger-causality between the variables, the LGDPI and LDFI are cointegrated, we can easily test the null hypothesis whether $L D F I$ does not Granger cause LGDPI, or LGDPI does not Granger cause LDFI. Use software EViews6.0 to test Granger-causality relationship between LGDPI and LDFI [3]. the test results shown as Table 10.

From Table 10, in critical value of $10 \%$, the null hypothesis of "LDFI does not Granger Cause LGDPI" is rejected; This shows there is one-way Granger causality between LDFI and LGDPI, that is, the growth of direct foreign investments impacts industrial economic growth, direct foreign investments growth is the causes of industrial economic growth, while industrial economic growth is not causality of the direct foreign investments growth.

\section{Conclusions and Recommendations}

A) Although the growth of GDPI and DFI are unstable, there is long-term stable equilibrium relationship between GDPI and DFI.

B) The growth of direct foreign investments is the causality of growth of GDPI. It can be known, the growth of direct foreign investments plays an important role of GDPI growth.

C) Foreign direct investment plays an important role in China's industrial economic growth in the short term and long term. Foreign direct investments keep stable equilibrium growth relationship to China's industrial economic growth. Foreign direct investment is an important part and driving force in China's foreign trade. Foreign direct investment is an important part and the driving force in China's foreign trade. Therefore, foreign direct investment should be encouraged in further to accelerate the development of China's foreign trade. On the one hand, China attract foreign investment policy orientation should be actively adjust, the foreign capital enterprise with high technology and high added value encouraged into China. On the other hand, to develop China's domestic processing trade enterprise's development, which has not lost comparative advantage industry development premise, further use of foreign advanced technology and management level to promote the upgrading of the industrial structure of China.

\section{Acknowledgment}

This work was supported by the Planned Science and Technology Project of China Hunan Provincial Science \& Technology Department under grant No.2012FJ3030, and The Vocational Education Subject of China Machinery Industry Education Association in 2011 under grant No. ZJJX11ZZ013.

\section{REFERENCES}

[1] Tan Yuanfa. Circular economy of equipment manufacturing $[\mathrm{M}]$. Beijing: China economic publishing house, 2010.

[2] Jeffrey M. Woddridge, Introductory Econometrics: A Modern Approach. Third Edition [M]. Beijing: Tsinghua University Press, 2007.

[3] Tan Yuanfa, Yin Ying, Cointegration Between the Growth of Industrial Economy and Foreign Trade [J]. Consume Guide,2008-3.

[4] Ugur S.S Ramazan. Energy consumption and GDP: Causality relationship in G-7 countries and emerging markets [J]. Energy Economics, 2003-25:33 37.

[5] Glasure Y U.Lee A R. Co-integration, error-correction and the relationship between GDP and Electricity: the case of South Korea and Singapore[J]. Resource and Electricity Economics,1997-20:17 25.

[6] Cheng B. S. An investigation of cointegration and causality between energy consumption and economic growth [J]. Journal of Energy Development ,1995-21:73 84 . 